DR MAY EL HADDAD (Orcid ID : 0000-0003-2328-685X)

Article type : Original Article

\title{
Perceptions of the impacts of introducing administrative support for nurse unit managers: A qualitative evaluation
}

KEY WORDS: clinical leadership, management, nurse unit manager, administrative burden, administrative support

SHORT RUNNING TITLE: Administrative support for nurse unit managers

\section{AUTHORS' NAMES AND AFFILIATIONS:}

May El Haddad

Graham Wilkinson

Lorraine Thompson

Annette Faithfull-Byrne

Cheryle Moss

May El Haddad RN, PhD, MACN

Adjunct Senior Lecturer,

School of Nursing, Midwifery and Paramedicine,

${ }^{1}$ University of the Sunshine Coast,

Locked bag 4, Maroochydore DC, Queensland 4558, Australia

Nurse Researcher,

${ }^{2}$ Sunshine Coast Hospital and Health Service,

PO Box 5340, Sunshine Coast MC, Queensland 4560, Australia

This article has been accepted for publication and undergone full peer review but has not been through the copyediting, typesetting, pagination and proofreading process, which may lead to differences between this version and the Version of Record. Please cite this article as doi: 10.1111 /jonm. 12860

This article is protected by copyright. All rights reserved. 


\section{Graham Wilkinson RN, MHSMan}

Director of Nursing, Nambour General Hospital Facility Manager,

${ }^{2}$ Sunshine Coast Hospital and Health Service,

PO Box 5340, Sunshine Coast MC, Queensland 4560, Australia

Adjunct Professor,

School of Nursing, Midwifery and Paramedicine,

${ }^{1}$ University of the Sunshine Coast,

Locked bag 4, Maroochydore DC, Queensland 4558, Australia

Tel: +61 753703629 E: graham.wilkinson@health.qld.gov.au

\section{Lorraine Thompson RN, PhD}

Nurse Educator Research,

${ }^{2}$ Sunshine Coast Hospital and Health Service,

PO Box 5340, Sunshine Coast MC, Queensland 4560, Australia

Tel: +61754705273 E: lorraine.thompson2@health.qld.gov.au

\section{Annette Faithfull-Byrne RN, RPN, MNsgEd}

Nursing Director Education,

${ }^{2}$ Sunshine Coast Hospital and Health Service,

PO Box 5340, Sunshine Coast MC, Queensland 4560, Australia

Adjunct Associate Professor,

School of Nursing, Midwifery and Paramedicine,

${ }^{1}$ University of the Sunshine Coast,

Locked bag 4, Maroochydore DC, Queensland 4558, Australia

Tel: +61 754705220 E: annette.faithfull-byrne@health.qld.gov.au

Cheryle Moss RN, PhD, FACN

Associate Professor,

Nursing and Midwifery,

${ }^{3}$ Monash University,

Clayton Campus, VIC 3800, Australia

Tel: +61399053469 E: cheryle.moss@monash.edu

This article is protected by copyright. All rights reserved. 


\section{CORRESPONDING AUTHOR:}

May El Haddad RN, PhD, MACN

Adjunct Senior Lecturer in Nursing,

School of Nursing, Midwifery and Paramedicine,

University of the Sunshine Coast,

Locked bag 4, Maroochydore DC, Queensland 4558, Australia

Tel: +61 422276762 E: melhadda@usc.edu.au

\section{ACKNOWLEDGMENTS:}

May El Haddad was employed by the Sunshine Coast Hospital and Health Service for the purpose of designing and undertaking this research project. This study is part of a project that received funding from the Queensland Government. The authors would like to thank the participants for their contribution and the health-service executive team for their support of the study.

\section{CONFLICT OF INTEREST STATEMENT (FOR ALL AUTHORS):}

The authors declare we have no conflict of interest.

\section{SOURCE OF FUNDING:}

This study is part of a project that received funding from the Queensland Government, Australia.

\section{ETHICAL APPROVAL}

The study was approved by the Prince Charles Hospital Human Research Ethics Committee in Brisbane (HREC/17/QPCH/268).

\section{CONTRIBUTION OF AUTHORS}

- $\mathrm{MEH}$ - chief investigator, project design, ethics, data collection, data analysis and lead writer of paper.

- GW - grant application, project design review, and review of paper.

- LT - project design review, ethics, data collection, data analysis and final review of paper.

- AFB - grant application, project design review, and editing of paper.

- $\mathrm{CM}$ - project design, ethics, data analysis and supervisor and co-writer of paper.

This article is protected by copyright. All rights reserved. 


\section{Abstract}

Aim: To evaluate the impacts of introducing administrative support for nurse unit managers (NUMs).

Background: Increased administrative load for NUMs is causing role stress and reducing opportunities for clinical leadership (State-wide Review, Queensland, Australia). In response, a health organisation implemented a clerical 'NUM Support Officer' (NSO) position.

Methods: Qualitative descriptive evaluation, convenience sample (37 NUMs and NSOs), focus groups (13) provided data that was thematically analysed (guided by Braun and Clarke's framework).

Results: Six impacts were identified: 1 ) improved NUM wellbeing; 2 ) more time to undertake clinical leadership; 3) greater efficiencies in finance, payroll and HR processes; 4) improved capacity for strategic leadership; 5) increased staff satisfaction and improved unit culture; and 6) improved succession planning.

Conclusion: Findings reveal significant gains and benefits from the introduction of administrative support for the NUM role for the NUMs and the units they manage.

Implications for nursing management: NUM role stress can negatively impact organisational climate, performance outcomes, and staff satisfaction and retention. Health organisations need to implement strategies to reduce the administrative burden for NUMs. The introduction of administrative support frees up time for NUMs to engage in clinical leadership, positively impacting organisational climate, performance outcomes, and staff satisfaction and retention.

Keywords: clinical leadership, management, nurse unit manager, administrative burden, administrative support.

\section{Background}

In this paper the results of an Australian based intervention to support nurse unit managers (NUMs) by reducing their administrative burden are reported. In Australia, NUMs are registered nurses who are accountable for leading clinical care and managing the business aspects of a ward or unit within healthcare organisations (ANMF, 2013). The term NUM has been used interchangeably in the literature with the terms nurse managers in the USA (IOM, 2011), ward managers in England (Locke, Leach, Kitsell, \& Griffith, 2011), senior charge nurse in Scotland (Rankin, McGuire, Mathews, Russell \& Ray, 2016) and charge nurse managers in New Zealand (McCallin \& Frankson, 2010). NUMs' accountabilities include quality patient care, staff satisfaction and retention, implementation of evidence-based practice, meeting budgetary requirements, and execution of organisational change (ANMF, 2013; Gunawan \& Aungsuroch, 2017; IOM, 2011). As the direct interface between healthcare executives and bedside nurses, NUMs play a pivotal role in supporting the achievement of positive healthcare and organisational outcomes (Gunawan, Aungsuroch \& Fisher, 2018; Simpson, Dearmon \& Graves, 2017; Wong, Cummings, \& Ducharme, 2013). Due to health system reform and restructuring, technological advances, higher acuity and faster turnover of patients, budgetary restrictions, and aging populations, the health care environment has become more complex and

This article is protected by copyright. All rights reserved. 
demanding for nurse managers in the healthcare industry (Duffield, Kearin, Johnston, \& Leonard, 2007; Udod, Cummings, Care, \& Jenkins, 2017; Warshawsky, 2018). As a result, there is increasing concern that the clinical leadership component of the NUM role is being eroded by increased administrative load instigating role stress for NUMs.

Internationally, role stress and challenges faced by NUMs are reported in the USA (Jones, McLaughlin, Gebbens \& Terhorst, 2015; Loveridge, 2017; McCright, Pabico \& Roux, 2018; Nelson, 2017; Shirey, McDaniel, Ebright, Fisher, \& Doebbeling, 2010; Simpson et al., 2017; Steege, Pinekenstein, Knudsen \& Rainbow, 2017) and Canada (Brown, Fraser, Wong, Muise, \& Cummings, 2013; Udod et al., 2017; Wong \& Laschinger, 2015). This is further supported by studies from New Zealand (McCallin \& Frankson, 2010), the UK (Locke et al., 2011; Rankin et al., 2016; Timmons, 2017) and wider Europe (Adriaenssens, Hamelink \& Van Bogart, 2017; Tewes \& Fischer, 2017). Challenges include inadequate preparation and support to undertake the leadership role, role ambiguity, increased span of control and increased administrative load reducing opportunities for NUMs to be clinical leaders (Gunawan et al., 2018). Significantly, role stress for NUMs potentially threatens their work-life balance, decision-making, quality of care and turnover intent (Steege et al., 2017; Udod et al., 2017), the recruitment and retention of NUMs (Brown et al., 2013; Hewko, Brown, Fraser, Wong, \& Cummings, 2015; Lee \& Cummings, 2008; Loveridge, 2017; Shirey et al., 2010), the creation of positive safety climate and work environment (Simpson et al., 2017), and the satisfaction and retention of staff (Cummings et al., 2018; Duffield, Roche, Blay \& Stasa, 2010; Morsiani, Bagnasco \& Sasso, 2017; Saleh et al., 2018).

The experience in Australia corroborates the international concerns related to the NUM role. Duffield and Franks (2001) warned that the restructuring of the Australian health-care system and the reduction in middle management positions has led to NUMs having to spend more time on administrative work and as a consequence having reduced capacity to supervise and support their staff. In a study of first-line managers over a 10-year period from 1989 to 1999, Duffield and colleagues (2001) reported that fewer managers $(72.7 \%)$ intended to stay in nursing management in 1999, in comparison to 1989 (84.2\%). Successive Australian studies continued to report similar findings. In 2008, a State-wide review of the NUM role by the Queensland Government (2008) highlighted a range of issues instigating role stress and dissatisfaction for NUMs. These issues include insufficient training and preparation to undertake the role, ambiguity of core role functions, extraneous tasks limiting the clinical leadership role of the NUM, including but not limited to spending significant time attending to non-clinical administrative tasks that can be delegated to a suitably qualified administrative assistant (Queensland Government, 2008). Recommendations from the reviews included measures to reduce the bureaucratic administrative burden for the NUM role and the need for clinical leadership education and mentoring (Queensland Government, 2008 \& 2011). The State-wide review findings are not unique and are consistent nationally (Duffield et al., 2007; Gaskin, Ockerby, Smith, Russell, \& O'Connell, 2012) and internationally (Gunawan et al., 2018; Loveridge, 2017; Simpson et al., 2017; Udod et al., 2017; Wong \& Laschinger, 2015).

In 2017, recognising the Queensland Government review findings and recommendations (2008 \& 2011), a public tertiary health organisation in regional Queensland introduced administrative support for NUMs by implementing a 'NUM Support Officer' (NSO) clerical position. A large study evaluated the impact and outcomes of this initiative; this paper reports the qualitative findings. A total of 30 NSO positions were employed and assigned to 45 NUMs in different clinical sites across the organisation. The organisation provided NSOs to NUMs who managed complex wards/teams and

This article is protected by copyright. All rights reserved. 
who had high administrative burden and reported working significant hours in excess of normal expectations. Key accountabilities of the NSO position were to undertake administrative tasks to reduce the administrative burden and free up time for NUMs to engage in clinical leadership. NSOs provide administrative and business support directly to NUMs (similar to an executive assistant). NSOs undertake administrative and clerical processes related to payroll, roster management, recruitment, financial and system reports (see Table 1).

Coincidentally, reports of two interventions from the UK (Locke et al., 2011) and the USA (Simpson et al., 2017) support the intent of the intervention reported in this paper. In a study evaluating the introduction of administrative assistants in the UK, ward managers reported a reduction in workload and greater job satisfaction (Locke et al., 2011). Similarly, the introduction of administrative assistants for NUMs in the USA, led to higher job satisfaction (Simpson et al., 2017). While the intervention reported in this paper was not informed by the work of Simpson et al. (2017) and Locke et al. (2011), there are parallels in what they report as interventions and outcomes.

\section{Methods}

\section{Research aim and design}

The aim of the qualitative component of the study was to evaluate the impacts of introducing administrative support for NUMs on their role, clinical leadership and units from the perspectives of NUMs and NSOs. Completed in 2018, this evaluative study utilised a qualitative descriptive design informed by Sandelowski (2000). Qualitative description draws from the general tenets of naturalistic inquiry (Sandelowski, 2000). This is the methodology of choice when straight descriptions of phenomena are desired leading to the presentation of the facts of the case, from the perspectives of participants, in everyday language (Sandelowski, 2000).

\section{Research setting}

The study was conducted at a large public tertiary health organisation in regional Queensland, Australia. In Australia, a tertiary health organisation is classically a teaching organisation associated with a major university; consisting of multiple campuses; and providing a wide range of services. The organisation employs over 2500 nurses and encompasses five hospitals with diverse inpatient, ambulatory and community services. It provides primary, secondary and tertiary care in a range of service groups. At the time of the study, while there were 60 NUMs employed with the organisation; only 45 NUMs had access to the 30 NSOs. Focus group participants were recruited from the 45 NUMs and 30 NSOs.

\section{Recruitment and data collection}

Ethics approval was granted and participation was voluntary. Related to selection criteria, any NUM who had access to NSOs and any NSO employed in the organisation were eligible to participate in the study. The primary investigator (MEH) who is a nurse but not involved in the organisation, sent an e-mail inviting all NSOs and NUMs who fitted the selection criteria to participate in a focus group

This article is protected by copyright. All rights reserved. 
interview. A convenience sample of NSOs ( $n=19 ; 63 \%$ of population) and NUMs ( $n=18 ; 40 \%$ of population) self-selected for participation. Data were collected between January and March 2018.

Focus groups as means for data collection were identified as logistically practical for the organisation; also they gave some flexibility to the participants regarding venue and timing of interview. Facilitation of small focus groups can strengthen participation, and participants may be more forthcoming with data due to group synergies (Ho, 2017). For participant convenience, interviews were held at three different hospitals. A total of 13 focus group interviews were undertaken separately, six with NUMs and seven with NSOs. Using a semi-structured open-ended interview guide, all interviews were of one hour duration and digitally-recorded. Two nurse researchers (MEH \& LT) conducted the interviews to sustain interview consistency and researcher availability to the participants. Table 2 contains information about the focus group participation. Focus groups were conducted each with 2-5 participants; this enabled participants and researchers to explore the questions and responses in some depth.

The same overarching interview question was asked of both NUM and NSO participants: 'What is the impact of the NSO position on the day to day operation of the clinical area?' Using a conversational style, follow up questions were open-ended and based on participants' interests and responses. Additionally, the researchers were interested in exploring participants' experiences and perspectives on contextual issues related to the composition and the implementation process of the NSO position.

\section{Data analysis}

All audio recordings were transcribed verbatim by a certified transcriber. Transcripts were analysed using descriptive thematic analysis. The method of thematic analysis was guided by the six phase approach described by Braun and Clarke (2006): 1. Familiarisation with the data, 2. Generating initial codes (systematic coding and collation of codes), 3. Grouping codes into themes, allocating relevant data to each theme; 4 . Reviewing themes for coherence and saturation, 5. Defining and refining each theme, generating meanings for each theme, and 6 . Producing the report with selected extracts, relating the analysis back to research question.

Two researchers (MEH \& LT) read all the transcripts to obtain a sense of the data and capture key concepts and jointly coded four transcripts (two NUMs and two NSOs) to develop a coding structure. All transcripts from the NUMs' focus groups were studied and coded, and then all transcripts from the NSOs' focus groups were studied and coded. The researchers noted high levels of similarity of content in both groups of transcripts. This gave the researchers confidence to analyse the data as a whole. Had there been key differences between the two groups, the data would have been reported by group and the similarities and differences noted.

Researchers strived to stay true to the primary data and the descriptions provided by the participants (Sandelowski, 2000). To increase validity and rigour and to achieve cross researcher coherence, three researchers (MEH, LT, CM) reviewed the coded data multiple times until consensus on the themes was reached. Remaining close to the primary data in a practical way, low inference in the description and naming of the themes was achieved (Sandelowski, 2000). The level of data saturation was noted during the thematic analysis, only codes that were strongly evidenced or saturated were utilised in the final themes. No coding software was used.

This article is protected by copyright. All rights reserved. 
No member checking of participants related to the themes was undertaken. However, throughout the focus group interviews, participants were asked if they agreed or disagreed with the comments being made, hence given the opportunity to reflect on what was being said. This allowed time for review and further comment and enhanced the integrity of the data. A comprehensive audit trail of research processes and decisions and field notes supported the credibility and rigour of the study. All researchers who participated in data collection and analysis had no direct relationship with any of the participants.

\section{Results}

\section{Participant demographics}

The NUM participants were mainly female and their time in the role ranged from 1-20 years, while the extent of their experience as nurses ranged from 9-35 years. NUM participants managed clinical units in different service groups across the health-service. Regarding their highest academic qualifications, $72 \%$ had post registration qualifications and $28 \%$ held only pre-registration qualifications.

Organisations calculate staffing load in headcount as well as full-time equivalent (FTE) terms. FTE calculations are a way of reporting staffing numbers in a standardised way. For example a full time employee is regarded as a 1.0 FTE. Two half time employees would each be $0.5 \mathrm{FTE}$ and together add 1.0 FTE to the workforce numbers. In this study, a mean of 42.5 staff reported to each NUM (range = 18-95, median $=38$, tri-modal mode $-26,30,38)$. In FTE terms, this was a mean of 33 staff FTE reported to each NUM (range $=16-60$, median $=29$, tri-modal mode $=20,28,60$ ). The mean of 33 staff FTE could mean that up to 50-60 staff may report to an individual NUM as many staff work part-time. Despite being supported by NSOs, NUMs reported working an average of 5 hours per week each in addition to their rosters. Table 3 contains information about the NUMs' demographics.

The NSO participants were mainly female and the majority were employed full-time. Most NSOs (part-time or full time) worked with more than one NUM. Table 4 contains information about the NSOs' demographics.

\section{Impacts of the NSO intervention}

Six impacts were identified thematically from the data (Figure 1); each impact revealed benefits from the introduction of administrative support for the NUM role. The impacts were improved NUM wellbeing; improved capacities of NUMs to undertake clinical leadership; improved administrative efficiencies in finance, payroll and human resource (HR) processes within their units; improved capacity for NUMs to be strategic leaders; improved staff satisfaction and unexpected positive impacts in the culture of the unit; and improved succession planning for the NUM role.

\section{Impact 1: Improved NUM wellbeing}

NUMs reported improved wellbeing and role satisfaction due to the NSO role. One NUM said "...I sleep a little bit better ...I couldn't live without her. ...they can troubleshoot a lot of little things for you" (NUM-12). It was identified that "...the impact of having a position [NSO] is actually critical ...for

This article is protected by copyright. All rights reserved. 
the NUM role. It takes a load of stress off that you simply don't need and you take it home with you" (NUM-14). These sentiments were echoed in all interviews with NUMs.

NSOs were aware of the significant impact their role was making on the NUMs' stress levels and sense of wellbeing. This was illustrated by an NSO suggesting "...taking the stress off them ... that's a good thing. Because an un-stressed manager is going to manage their staff better and the staff are going to be happier" (NSO-10).

NUMs reported having more time to develop as leaders and to participate in professional development activities. Prior to the NSOs, NUMs felt they didn't have the time to engage in professional development activities.

“...normally, I can't go [participate in professional development] ... Whereas now, because you've got someone there that will keep an eye on things, you're more comfortable to go, ... So that's probably a big benefit for us too because as NUM's you rarely go on PD leave" (NUM-7).

Many participants wanted to tell the researchers about the challenges NUMs have experienced in their role prior to the introduction of the NSO. This was reflected in the words of an NSO: "I would hate to have seen their workload before we got here because I don't see how they could've managed" (NSO-15). Most NUMs reported a significant drop in the number of hours worked on administrative tasks and overtime due to the implementation of the NSO intervention.

This administrative burden for some NUMs came at a high personal cost. This resulted in feeling overwhelmed, stressed, diminished clinical confidence, and extension of the working day to manage the heavy workload. This sentiment, illustrated by the words of two NUMs, was echoed in most NUM interviews:

“... I don't know how I did anything before they came along. ... just constantly overwhelmed and hassled. ... I didn't get home until 7:00pm at night and you're here at 6:30am in the morning" (NUM-12).

"...you lose the [clinical] confidence ... to get out and make the decisions, because you haven't done it for a long time" (NUM-3).

\section{Impact 2: More time to undertake clinical leadership}

As a result of the NSO, NUMs reported more time to round on patients and staff and to undertake clinical leadership. From this, they reported higher engagement, relational transparency, trust and more open discussion in the work environment. NUMs believed they were able to drive practice based on their own expertise as nurses.

"I've been able to do more leadership, change management ...I don't know how I ever got out of my office before having an NSO" (NUM-6).

"You can invest time into your staff and the patients" (NUM-9).

"I've got time to think about ... where my staff are clinically ... and have we got our competencies" (NUM-13).

This article is protected by copyright. All rights reserved. 
"...first thing in the morning, I can go and say hello to everybody in the department, and see where the problems are before the problems develop" (NUM-18).

"...probably the biggest benefit is to be able to work on the floor, to get your hands dirty again and work with the people" (NUM-7).

Several NUMs commented on now having the time to round on their staff, engage with them and support them. When NUM-9 stated that "You can engage more [with staff] ... as a NUM before, I always felt like I had to be somewhere else", all NUMs in the room nodded their heads in agreement.

NSOs reflected on the daily challenges that confronted NUMs and how they had to juggle their competing priorities as illustrated below:

"...they had to have everything in by 10 o'clock. It's just impossible when they come on and they've got to do handover in the mornings, and they've got their doctors' rounds, anything that has arisen from the previous night or evening. ...they were on such tight time limits" (NSO-5).

Many commented on how their role contributed to NUMs having more time to be clinical leaders, spend time on the floor clinically, round on staff and patients, and be involved in doctors' rounds:

"... [NUM] is able to have the bird's-eye view of what's going on, so you can go, 'that's not working, so let's try this'. ...it helps for the NUM to ...oversee it rather than get bogged down in the detail" (NSO-4).

"...it frees up the NUM to assist with clinical related issues, supporting staff" (NSO-7).

\section{Impact 3: Greater efficiencies in finance, payroll and HR processes}

Participants commented on how NSOs created major efficiencies in processes related to recruitment and on-boarding of staff, payroll, monetary, and general administration. NSOs commented on how their positions have improved administrative efficiencies:

"... with the staff, we've [NSOs] built a good rapport ... If they have payroll issues now, they'll contact us. They'll still cc in their NUM ... they're feeling a bit more confident with getting their payroll issues rectified" (NSO-15).

"There are definitely less pay issues with staff compared to when I started. I would have many ...pay errors, and that has dramatically decreased since our role has been implemented" (NSO-7).

"...recruitment gets done a lot quicker than when the NUMs were having to chase reference reports ..." (NSO-19).

NUMs also commented on these efficiencies:

"Within a week of short-listing you can have your candidates ready. ... Before, that might take three to four weeks to work into your everyday work" (NUM-10).

"New staff, when they come in, all the paperwork that has to be done to get swipe cards ... and other things, she'll help with" (NUM-1).

This article is protected by copyright. All rights reserved. 
NUMs commented on the impact of the NSO position in relation to improving monetary efficiencies.

"...if you analyse it from a cost-effective point of view ...there aren't half as many payroll issues with these NSOs. That has a knock-on effect within the health-service, cost effectiveness" (NUM-9).

"...they [NSOs] look at all the overtime, or people that would get paid overtime from changing shifts and things that you might not realise, ...before the roster goes in" (NUM-7).

NSOs improved the administrative processes related to system reports that are part of the NUM responsibilities. NUMs still must review and sign off on almost all the work but the NSOs help with the day to day clerical preparation and management and assist with having more timely systems and better infrastructure to manage the workload.

"...cost centre meetings are much more structured. We get together ... the week prior to cost centre meeting ... So you go into the meeting prepared" (NUM-8).

"...she goes through and checks everything for me ... and flags a lot of things to me that I don't have time to get round to do" (NUM-15).

\section{Impact 4: Improved capacity for NUMs to be strategic leaders}

Introducing NSOs improved the capacity for NUMs to be strategic leaders and to use pertinent data to inform decision making. NUMs unanimously reported that they now have more time to think strategically and make practical decisions to link their work to organisational outcomes:

"...before I was very reactive just trying to get through the day to get everything that needed to be done ... I can now think outside the square whereas I could never have done that before because I was too bogged down" (NUM-12).

"I've got time to think about where we're heading strategically and what we need to do" (NUM-13).

One NSO explained that "... when NUMs are bogged down having to do payroll ... they are missing the opportunity to present data ... to give the executive the information needed to run the hospital" (NSO-4).

\section{Impact 5: Increased staff satisfaction and improved unit culture}

Unexpected positive impacts on the culture of the unit and staff satisfaction were reported as a result of NSOs supporting the NUMs. Most NUMs had observed improvements in staff satisfaction due to NUMs having more time to be present and engage with them.

"...the team are happier, the doctors are happier - everybody loves to have that one go-to person [NUM] who's constantly available and constantly there ... for allied health, for food services, for executive, for educators, for everybody" (NUM-3).

“...makes your team happier ...you don't have to deal with low morale ... so it's a win/win on all fronts" (NUM-10).

This article is protected by copyright. All rights reserved. 


\section{Impact 6: Improved succession planning for NUM role}

Participants reported that the NSO role had a positive impact on succession planning, particularly in relation to clinical nurses (CNs) stepping into the NUM role and learning the relevant systems and processes.

“...now my NUM reliever doesn't have to sit there for two hours and go, "I don't know how to write this report." ...she can lean on my NSO for help" (NUM-1).

“...new NUMs coming in, or acting NUMs, ...you'd get more buy in, because they're not going to be so overwhelmed - there's somebody else who knows the paperwork" (NUM-2).

One NSO reported that "my NUM is on leave, and the CN stepping in is so thankful to have me there because she's learning the role, and to be able to just pass admin things, ...staff enquiries off to me, is a huge weight off her" (NSO-8).

\section{Making the NSO-NUM partnership work}

The research uncovered an array of local practices and mechanisms that were employed by NUMs and NSOs to make the partnership work. A summary of these practices appear in Table 5.

\section{Discussion}

NUMs play a critical role in supporting the achievement of positive healthcare and organisational outcomes (Gunawan et al., 2018; Simpson et al., 2017; Wong et al., 2013). Implementing administrative support for NUMs to reduce their administrative burden was a significant workforce reform strategy. The research identified significant positive impacts from the NSOs for the NUM role and their units. NSO and NUM participants also revealed how they made this partnership work. There were no negative impacts from the initiative for the units or the organisation reported by participants in this study.

The impetus for the NSO intervention was concern for the expanded administrative burden and workload of NUMs. Literature confirms that high work-loads and administrative burden for middle managers in healthcare are "creating extreme jobs with long hours, high intensity and fast pace ... [these] roles can be rewarding but carry implications for work life-balance and stress" (Buchanan, Denyer \& Jaina, 2013, p. V). It is important that healthcare organisations create innovative remedies and interventions to correct these evolving imbalances. In nursing the creation of the NSO role may be a partial solution to reducing NUMs' role stress in this changing healthcare work environment.

The NSO intervention reduced the administrative burden of the NUMs. As the demographic data revealed NUMs still had a significant workload and overwork occurred. It is important to recognise that the NSO intervention is not a total solution; there is continued need to refine the work of NUMs and to find innovative ways to support them.

To address the complexity of the NUM role and reduce role stress multiple strategies are needed (Shirey et al., 2010). Some authors (McCright et al., 2018; Simpson et al., 2017) report the intervention of reducing or controlling nurse managers' span of control to reduce role overload, role complexity and role stress. It is likely that managing NUMs' span of control is another important consideration (Simpson et al., 2017; Wong et al., 2014).

This article is protected by copyright. All rights reserved. 
Not only did the NSOs reduce the administrative burden of NUMs, they also improved the clinical units' efficiencies in payroll and HR. Administrative staff are more likely to have better skills in managing finance, payroll and HR systems. Additionally, NSOs had dedicated time to focus on these activities; whereas the NUMs experienced these administrative tasks as competing with their clinical leadership. Locke et al. (2011) also found ward manager administrative assistants created greater cost and administrative efficiencies.

The key accountabilities of the NSO role presented in Table 1 had similarities to the responsibilities of the administrative assistance as reported by Locke et al., (2011) and Simpson et al. (2017). The NSOs and the NUMs thought that the role accountabilities were realistic and workable for the NSOs, NUMs and the units.

Given the consequences of role stress on NUMs' work-life balance, decision-making, quality of care and turnover intent (Nelson, 2017; Steege et al., 2017; Udod et al., 2017) the reporting of greater levels of satisfaction and wellbeing as a result of having NSOs is a significant finding. Locke et al. (2011) and Simpson et al. (2017) reporting outcomes from the introduction of administrative assistance also found higher levels of satisfaction in nurse managers, because they could spend more time on the wards with patients and staff.

Baggett et al. (2016) described the importance and positive effects that the emotion of 'feeling cared for' in the workplace has on employees. Providing relief and reducing administrative burden for NUMs is likely to increase their sense of being cared for, and by implication may result in overall health benefit to role incumbents and improve job satisfaction and retention.

The NSO intervention supported NUMs to undertake greater levels of clinical and strategic leadership and to affect the culture of the unit. Rankin et al. (2016) report that increasing time for nurse managers to be clinical leaders, to be more visible and accessible to staff is an important mechanism for improving quality of care and staff experiences.

The reduction in administrative burden for NUMs freed them to engage more relationally with their staff. The impacts found confirm findings of other nursing studies where the relational work of the leader has significant impacts for teams (Morsiani et al., 2017). This is important because of the reported impacts of relational leadership on nurse performance, patient outcomes, staff job satisfaction and intent to stay (Brady \& Cummings, 2010; Cowden, Cummings \& Profetto-McGrath, 2011; Cummings et al., 2010; Cummings et al., 2018; Wong et al., 2013).

Learning the NUM role through trial and error has been reported by studies over the past decade (Paliadelis, Cruickshank \& Sheridan, 2007; Platt \& Foster, 2008; Titzer, Phillips, Tooley, Hall \& Shirey, 2013) through to current time (Bradley \& Moore, 2019; Phillips, Evans, Tooley \& Shirey, 2018). A similar trend was indicated by the demographic data in the current study. Because of the limited preparation and training for the NUM role, the provision of staff development and enabling NUMs to participate are workplace imperatives. Literature (Bradley \& Moore, 2019; McCallin \& Frankson, 2010) and our findings confirmed that heavy workloads can prevent NUMs from engaging in professional development opportunities. NSO support enabled the NUMs in our study to plan for and attend staff development. Warshawsky, Wiggins and Rayens (2016) found that professional development for nurse managers is critical for reducing turnover intentions. The provision of professional development is likely to require supplementation with/by formal leadership education (Ramseur, Fuchs, Edwards \& Humphreys, 2018).

This article is protected by copyright. All rights reserved. 
The NSO intervention enabled the NUMs to have more time to succession plan staff in their units for future NUM work. Literature reveals that the profession has issues with attracting and preparing nurses to take up the NUM role (Bradley \& Moore, 2019; McCright et al., 2018; Phillips et al., 2018). What is interesting about our results is that the presence of the NSO in the unit helped nurses to feel more confident acting up into the NUM role. The reassurance of the NSOs' knowledge of the administrative systems was an informal factor influencing this confidence. By implication it is likely that NSO and NUM support for staff acting up would improve staff members' readiness for the leadership role (LaCross, Hall \& Boerger, 2019). Additionally, the NUMs had more time to consider what was needed in succession planning and to strategise who and how the succession planning should occur in the unit. Phillips et al. (2018) identified that this may aid nurse manager preparation and retention.

NUMs and the wider organisation should incorporate knowledge about the factors that influence succession planning into formal and informal processes (LaCross et al., 2019; Phillips et al., 2018; Ramseur et al., 2018; Titzer et al., 2013). Additionally, the transition and learning needs of novice nurse managers could be met by professional development and succession planning initiatives (Djukic, Jun, Kovner, Brewer \& Fletcher, 2017; Gunawan \& Aungsuroch, 2017; Gunawan, et al., 2018 Siren \& Gehrs, 2018). Improving capacity to attract new incumbents to the NUM role is significant given earlier warnings that staff nurses are reluctant to step into the role of NUM, with lack of support being indicated as the primary reason (Duffield \& Franks, 2001; Hewko, et al., 2015; Queensland Government, 2008).

This study indicates positive impacts from the implementation of the NSO positions. NSOs and NUMs worked together to make the partnership work. Incorporating administrative support can reduce NUM administrative burden, advance capacity for clinical leadership, and advance unit culture and staff satisfaction. More organisations need to trial the intervention and investigate the impacts on staff satisfaction and unit culture. A cost-benefit study would assist clarification of organisation gains over the actual cost of the NSO intervention.

The increased capacities for NUMs to provide more clinical and strategic leadership, as a result of the intervention, must make a difference to clinical care, teams and by implication the level of functioning within the nursing division. Improvements such as these require further investigation and reporting. The qualitative findings raise important possibilities for future interventions aimed at strengthening the leadership capacities of NUMs.

\section{Limitations of the study}

While the location and size of the study prevent generalisation, the impacts identified in the evaluation provide insights that should be translatable in other contexts. Convenience sampling and self-reporting limit the range of reportable perspectives. However, the six themes were sufficiently saturated to provide the basis for further study and for considered application in related clinical contexts. This study rests solely on the perspectives from two groups, NSOs and NUMs related to the intervention. The perceptions of staff and executive leaders were not explored and may have provided other insights.

This article is protected by copyright. All rights reserved. 


\section{Implications for nursing management}

Increased administrative load for NUMs causes role stress and reduces opportunities for clinical leadership. This has the potential to negatively impact organisational climate, performance outcomes, and staff satisfaction and retention. This makes it critical for health organisations to implement measures/strategies that can mitigate NUMs' role stress and increase their job satisfaction, retention and sense of wellbeing. Administrative support for NUMs is a mitigation strategy that provides positive impacts for NUMs, for their leadership, their units and the organisation. The implementation of the NSO position to reduce the administrative burden and free up time for NUMs to engage in clinical leadership, is a significant workforce reform initiative.

\section{Acknowledgements}

The authors would like to thank the participants for their contribution and the health-service executive team for their support of the study.

\section{References}

Adriaenssens, J., Hamelink, A. \& Van Bogaert, P. (2017). Predictors of occupational stress and wellbeing in first-line nurse managers: A cross-sectional survey study. International Journal of Nursing Studies, 73, 85-92. DOI: 10.1016/j.ijnurstu.2017.05.007

Australian Nursing and Midwifery Federation (ANMF) - Victorian Branch. (2013). The Role of the Nurse/Midwife Unit Manager. Retrieved Nov 13, 2018, from https://www.anmfvic.asn.au/ /media/files/anmf/vic\%20branch\%20policies\%20and\%20position\%20 statements/num_position_statement.pdf

Baggett, M., Giambattista, L., Lobbestael, L., Pfeiffer, J., Madani, C., Modir, R., Zamora-Flyr, M. M. \& Davidson, J. E. (2016). Exploring the human emotion of feeling cared for in the workplace. Journal of Nursing Management, 24(6), 816-824. DOI: 10.1111/jonm.12388

Bradley, J. M. \& Moore, L. W. (2019). The perceptions of professional leadership coaches regarding the roles and challenges of nurse managers. The Journal of Nursing Administration, 49(2), 105-109. DOI: 10.1097/NNA.0000000000000718

Brady, G. P. \& Cummings G. G. (2010). The influence of nursing leadership on nurse performance: a systematic literature review. Journal of Nursing Management, 18(4), 425-439. DOI: 10.1111/j.13652834.2010.01100.x

Braun, V., \& Clarke, V. (2006). Using thematic analysis in psychology. Qualitative Research in Psychology, 3(2), 77-101. http://dx.doi.org/10.1191/1478088706qp063oa

Brown, P., Fraser, K., Wong, C. A., Muise, M. \& Cummings, G. (2013). Factors influencing intentions to stay and retention of nurse managers: a systematic review. Journal of Nursing Management, 21(3), 459-472. DOI: 10.1111/j.1365-2834.2012.01352.x

This article is protected by copyright. All rights reserved. 
Buchanan, D. A., Denyer, D., Jaina, J., Kelliher, C., Moore, C. Parry, E. \& Pilbeam, C. (2013). How do they manage? A qualitative study of the realities of middle and front-line management work in healthcare. Health Services Delivery Research, 1(4). DOI: 10.3310/hsdr01040

Cowden, T., Cummings, G. \& Profetto-McGrath, J. (2011). Leadership practices and staff nurses intent to stay: a systematic review. The Journal of Nursing Management, 19(4), 461-477. DOI: 10.1111/j.1365-2834.2011.01209.x

Cummings, G. G., McGregor, T., Davey, M., Lee, H., Wong, C. A., Lo, E., Muise, M. \& Stafford, E. (2010). Leadership styles and outcome patterns for the nursing workforce and work environment: A systematic review. International Journal of Nursing Studies, 47(3), 363-385. DOI:

10.1016/j.ijnurstu.2009.08.006

Cummings, G. G., Tate, K., Lee, S., Wong, C. A., Paananen, T., Micaroni, S. P.M. \& Chatterjee, G. E. (2018). Leadership styles and outcome patterns for the nursing workforce and work environment: A systematic review. International Journal of Nursing Studies, 85, 19-60.

https://doi.org/10.1016/j.ijnurstu.2018.04.016

Djukic, M., Jun, J., Kovner, C., Brewer, C. \& Fletcher, J. (2017). Determinants of job satisfaction for novice nurse managers employed in hospitals. Health Care Management Review, 42(2), 172-183. DOI: 10.1097/HMR.0000000000000102

Duffield, C., \& Franks, H. (2001). The role and preparation of first-line nurse managers in Australia: Where are we going and how do we get there? Journal of Nursing Management, 9(2), 87-91. DOI: 10.1111/j.1365-2702.2010.03478.x

Duffield, C., Kearin, M., Johnston, J., \& Leonard, J. (2007). The impact of hospital structure and restructuring on the nursing workforce. Australian Journal of Advanced Nursing, 24(3), 42-46.

Duffield, C., Moran, P., Beutel, J., Bunt, S., Thornton, A., Wills, J., Cahill, P. \& Franks, H. (2001). Profile of first-line nurse managers in New South Wales, Australia, in the 1990s. Journal of Advanced Nursing, 36(6), 785-793.

Duffield, C., Roche, M. A., Blay, N. \& Stasa, H. (2010). Nursing unit managers, staff retention and the work environment. Journal of Clinical Nursing, 20(1-2), 23-33. DOI:

10.1111/j.13652702.2010.03478.x

Gaskin, C. J., Ockerby, C. M., Smith, T. R., Russell, V. \& O'Connell, B. (2012). The challenges acute care nurse unit managers face and the strategies they use to address them: Perceptions of directors of nursing and nurse unit managers. Journal of Management \& Organization, 18(5), 625-640. DOI: 10.5172/jmo.2012.18.5.625

Gunawan, J. \& Aungsuroch, Y. (2017). Managerial competence of first-line nurse managers: A concept analysis. International Journal of Nursing Practice, 23, e12502, 1-7. DOI 10.1111/ijn.12502

Gunawan, J., Aungsuroch, Y. \& Fisher, M. L. (2018). Factors contributing to managerial competence of first-line nurse managers: A systematic review. International Journal of Nursing Practice, 24, e12611, 1-12. DOI: 10.1111/ijn.12611

This article is protected by copyright. All rights reserved. 
Hewko, S. J., Brown, P., Fraser, K. D., Wong, C. A. \& Cummings, G. G. (2015). Factors influencing nurse managers' intent to stay or leave: a quantitative analysis. Journal of Nursing Management, 23(8), 1058-1066. DOI: 10.1111/jonm.12252

Ho, D. (2017). The focus group interview: Rising to the challenge in qualitative research methodology. Australian Review of Applied Linguistics, 29(1), 05. DOI: 10.2104/aral0605

Institute of Medicine (IOM) (2011). The Future of Nursing: Leading Change Advancing Health. Washington, DC: The National Academies Press. Retrieved Nov 3, 2018, from http://nacns.org/wpcontent/uploads/2016/11/5-IOM-Report.pdf

Jones, D., McLaughlin, M., Gebbens, C. \& Terhorst, L. (2015). Utilizing a scope and span of control tool to measure workload and determine supporting resources for nurse managers. The Journal of Nursing Administration, 45(5), 243-249. DOI: 10.1097/NNA.0000000000000193

LaCross, E., Hall, N. \& Boerger, J. A. (2019). Nurse manager succession planning - evaluating a pilot program's effect on self-perception of readiness. The Journal of Nursing Administration, 49(6), 331335. DOI: 10.1097/NNA.0000000000000761

Lee, H. \& Cummings, G. G. (2008). Factors influencing job satisfaction of front line nurse managers: a systematic review. Journal of Nursing Management, 16(7), 768-783. DOI: 10.1111/j.13652834.2008.00879.x

Locke, R., Leach, C., Kitsell, F. \& Griffith, J. (2011). The impact on the workload of the ward manager with the introduction of administrative assistants. Journal of Nursing Management, 19(2), 177-185. DOI: $10.1111 / j .1365-2834.2011 .01229 . x$

Loveridge, S. (2017). Straight talk: Nurse manager role stress. Nursing Management, 48(4), 20-27. DOI: 10.1097/01.NUMA.0000514058.63745.ad

McCallin, A. M. \& Frankson, C. (2010). The role of the charge nurse manager: a descriptive exploratory study. Journal of Nursing Management, 18(3), 319-325. DOI: 10.1111/j.13652834.2010.01067.x

McCright, M., Pabico, C., Roux, N. (2018). Addressing manager retention with the Pathway to Excellence ${ }^{\circledR}$ framework. Nursing Management, 49(8), 6-8. DOI:

10.1097/01.NUMA.0000542293.75001.38

Morsiani, G., Bagnasco, A. \& Sasso, L. (2017). How staff nurses perceive the impact of nurse managers' leadership style in terms of job satisfaction: a mixed method study. Journal of Nursing Management, 25(2), 119-128. DOI: 10.1111/jonm.12448

Nelson, K. E. (2017). Nurse manager perceptions of work overload and strategies to address it. Nurse Leader, 5(6), 406-408. DOI: 10.1016/j.mnl.2017.09.009

Paliadelis, P., Cruickshank, M. \& Sheridan, A. (2007). Caring for each other: how do nurse managers manage their role? Journal of Nursing Management, 15(8), 830-837. DOI: 10.1111/j.13652934.2006.00754.x

This article is protected by copyright. All rights reserved. 
Phillips, T., Evans, J. L., Tooley, S. \& Shirey, M. R. (2018). Nurse manager succession planning: A costbenefit analysis. Journal of Nursing Management, 26, 238-243. DOI: 10.1111/jonm.12512

Platt, J. F. \& Foster, D. (2008). Revitalizing the charge nurse role through a bespoke development programme. Journal of Nursing Management, 16(7), 853-857. DOI: 10.1111/j.1365-

2834.2008.00939.x

Queensland Government (2008). Review of the nurse unit manager role, final report. Brisbane:

Queensland Government.

Queensland Government (2011). Nurse unit manager project - Strengthening the leadership capacity and capability of our nurse leaders, Report. Brisbane: Queensland Government.

Ramseur, P., Fuchs, M. A., Edwards, P. \& Humphreys, J. (2018). The implementation of a structured nursing leadership development program for succession planning in a health system. The Journal of Nursing Administration, 48(1), 25-30. DOI: 10.1097/NNA.0000000000000566

Rankin, J., McGuire, C., Matthews, L., Russell, M. \& Ray, D. (2016). Facilitators and barriers to the increased supervisory role of senior charge nurses: a qualitative study. Journal of Nursing Management, 24(3), 366-375. DOI: 10.1111/jonm.12330

Saleh, U., O'Connor, T., Al-Subhi, H., Alkattan, R., Al-Harbi, S. \& Patton, D. (2018). The impact of nurse managers' leadership styles on ward staff. British Journal of Nursing, 27(4), 197-203.

Sandelowski, M. (2000). Focus on research methods - whatever happened to qualitative description? Research in Nursing and Health, 23, 334-340. DOI: 10.1002/1098-240X(200008)23:4\%3C334::AIDNUR9\%3E3.0.CO;2-G

Shirey, M. R., McDaniel, A. M., Ebright, P. R., Fisher, M. L., \& Doebbeling, B. N. (2010). Understanding nurse manager stress and work complexity: Factors that make a difference. Journal of Nursing Administration, 40(2), 82-91.

Simpson, B. B., Dearmon, V. \& Graves, R. (2017). Mitigating the impact of nurse manager large spans of control. Nursing Administration Quarterly, 41(2), 178-186. DOI: 10.1097/NAQ.0000000000000214

Siren, A. \& Gehrs, M. (2018). Engaging nurses in future management careers: perspectives on leadership and management competency development through an internship initiative. Nursing Leadership, 31(4), 36-49.

Steege, L. M., Pinekenstein, B. J., Knudsen, E'. A. \& Rainbow, J. G. (2017). Exploring nurse leader fatigue: a mixed methods study. Journal of Nursing Management, 25(4), 276-286. DOI: 10.1111/jonm.12464

Tewes, R. \& Fischer, T. (2017). Too busy to lead? Current challenges for German nurse leaders (an Editorial). Journal of Nursing Management, 25(1), 1-3. DOI: 10.1111/j.1365-2834.2008.00939.x

Timmons, S. A. (2017). Tensions within management roles in healthcare organisations. Nursing Management, 24(1), 31-37. DOI: 10.7748/nm.2017.e1569

This article is protected by copyright. All rights reserved. 
Titzer, J., Phillips, T., Tooley, S., Hall, N. \& Shirey, M. (2013). Nurse manager succession planning: synthesis of the evidence. Journal of Nursing Management, 21, 971-979. DOI: 10.1111/jonm.12179

Udod, S., Cummings, G. G., Care, W. D. \& Jenkins, M. (2017). Role stressors and coping strategies among nurse managers, Leadership in Health Services, 30(1), 29-43. DOI: 10.1108/LHS-04-2016-0015

Warshawsky, N. (2018). Promote nurse manager job satisfaction and retention. American Nurse Today, 13(8), 33-34.

Warshawsky, N. E., Wiggins, A. T., Rayens, M. K. (2016). The Influence of the Practice Environment on Nurse Managers' Job Satisfaction and Intent to Leave. The Journal of Nursing Administration, 46(10), 501-507. DOI: 10.1097/NNA.0000000000000393

Wong, C. A., Cummings, G. G. \& Ducharme, L. (2013). The relationship between nursing leadership and patient outcomes: a systematic review update. Journal of Nursing Management, 21(5), 709-724. DOI: $10.1111 /$ jonm.12116

Wong, C. A., Elliott-Miller, P., Laschinger, H., Cuddihy, M., Meyer, R. M., Keatings, M., Burnett, C., \& Szudy, N. (2014). Exploring managers' views on span of control: more than a headcount. Nurse Leadership, 27(1), 45-61.

Wong, C. A., Laschinger, H. K. S. (2015). The influence of frontline manager job strain on burnout, commitment and turnover intention: A cross-sectional study. International Journal of Nursing Studies, 52(12), 1824-1833. DOI: 10.1016/j.ijnurstu.2015.09.006

This article is protected by copyright. All rights reserved. 
Table 1: List of bureaucratic administrative activities for the NSO role

\begin{tabular}{|c|}
\hline $\begin{array}{l}\text { Category: Payroll - Examples include: } \\
\text { - Complete and submit employee movement forms, higher duties forms, leave forms and change to roster forms } \\
\text { - Organise workcover claim } \\
\text { - Liaise with payroll regarding data translation issues } \\
\text { - Resubmit old or missing forms } \\
\text { - Assist staff and liaise with payroll over payroll matters and queries (e.g. underpayments and overpayments) }\end{array}$ \\
\hline $\begin{array}{l}\text { Category: Roster Management - Examples include: } \\
\text { - Revise published rosters and input changes into Trendcare } \\
\text { - Provide rosters to payroll } \\
\text { - } \text { Adjust rosters and confirm accuracy with payroll }\end{array}$ \\
\hline $\begin{array}{l}\text { Category: Stock/lnventory - Examples include: } \\
\text { - Order and organise storage of clinical supplies and stationary } \\
\text { - Manage work orders and purchase requisitions }\end{array}$ \\
\hline $\begin{array}{l}\text { Category: Recruitment - Examples include: } \\
\text { - Organise interview timetables and venues } \\
\text { - Complete paperwork for criminal history checks and reference checks } \\
\text { - Checking credentials and registration } \\
\text { - Organise induction processes and support } \\
\text { - Process paperwork to Human Resources department }\end{array}$ \\
\hline $\begin{array}{l}\text { Category: Monthly System Reports - Examples include: } \\
\text { - Generate and summarise the fatigue penalty reports } \\
\text { - Generate and summarise the overtime and TOIL reports } \\
\text { - Generate and summarise the cost-centre management reports and the position occupancy reports } \\
\text { - Prepare the leave planner / leave excess report }\end{array}$ \\
\hline $\begin{array}{l}\text { Category: Mandatory Training - Examples include: } \\
\text { - Prepare and review staff compliance records/reports } \\
\text { - Provide same data to NUM, individual staff and other relevant people }\end{array}$ \\
\hline $\begin{array}{l}\text { Category: Administration Work - Examples include: } \\
\text { - File and archive relevant documents/records } \\
\text { - Organise appointments for and file completed performance and development (PaD) plans } \\
\text { - Prepare minutes and agendas } \\
\text { - Book venues/rooms for meetings, interviews and other planned events } \\
\text { - Process and file complaints and compliments } \\
\text { - Manage/coordinate IT issues - system access and computer issues }\end{array}$ \\
\hline
\end{tabular}

Table 2 - Summary of focus group (FG) interviews

\begin{tabular}{|c|c|c|c|c|}
\hline Participants & $\begin{array}{c}\text { Hospital } 1 \\
\text { (500 bed hospital) } \\
\end{array}$ & $\begin{array}{c}\text { Hospital } 2 \\
\text { (200 bed hospital) }\end{array}$ & $\begin{array}{c}\text { Hospital } 3 \\
\text { (50 bed hospital) } \\
\end{array}$ & $\begin{array}{c}\text { Total \# of } \\
\text { Participants }\end{array}$ \\
\hline NUMs & $\begin{array}{l}\text { FG1: } 2 \text { Participants } \\
\text { FG2: } 3 \text { Participants } \\
\text { FG3: } 3 \text { Participants }\end{array}$ & $\begin{array}{l}\text { FG4: } 2 \text { Participants } \\
\text { FG5: } 3 \text { Participants }\end{array}$ & FG6: 5 Participants & 18 \\
\hline NSO & $\begin{array}{l}\text { FG7: } 3 \text { Participants } \\
\text { FG8: } 2 \text { Participants } \\
\text { FG9: } 3 \text { Participants } \\
\text { FG10: } 3 \text { Participants } \\
\text { FG11: } 3 \text { Participants }\end{array}$ & FG12: 3 Participants & FG13: 2 Participants & 19 \\
\hline
\end{tabular}

This article is protected by copyright. All rights reserved. 
Table 3 - Summary of NUMs' demographic data

\begin{tabular}{|c|c|c|c|c|c|c|}
\hline Characteristics & $\%$ & Number & Range & Mean & Median & Mode \\
\hline \multicolumn{7}{|l|}{ PERSONAL DEMOGRAPHICS } \\
\hline \multicolumn{7}{|l|}{ Sex: } \\
\hline Female & 83 & 15 & & & & \\
\hline Male & 17 & 3 & & & & \\
\hline Years as RN & & & $9-35$ & 25 & 25.5 & 25 \\
\hline Years as NUM & & & $1-20$ & 7 & 4 & $1 \& 3$ \\
\hline \multicolumn{7}{|l|}{ Highest education } \\
\hline Hospital certification & 6 & 1 & & & & \\
\hline Bachelor degree & 22 & 4 & & & & \\
\hline Master degree & 22 & 4 & & & & \\
\hline Post-graduate Qualifications & 50 & 9 & & & & \\
\hline Doctorate & 0 & 0 & & & & \\
\hline \multicolumn{7}{|l|}{ Currently studying } \\
\hline Yes & 17 & 3 & & & & \\
\hline No & 83 & 15 & & & & \\
\hline \multicolumn{7}{|l|}{ DEMOGRAPHICS OF UNIT } \\
\hline Number of staff & & & $18-95$ & 42.5 & 38 & $26,30 \& 38$ \\
\hline Number of FTE & & & $16-60$ & 33 & 29 & $20,28 \& 60$ \\
\hline \multicolumn{7}{|l|}{ Service Group } \\
\hline Medical & 44 & 8 & & & & \\
\hline Surgical & 39 & 7 & & & & \\
\hline Women's \& Families & 17 & 3 & & & & \\
\hline \multicolumn{7}{|c|}{ DEMOGRAPHICS ASSOCIATED WITH ADMIN BURDEN } \\
\hline Average overtime hours/week & & & $0-10$ & 5 & 4.5 & 7 \\
\hline FTE of NSO support & & & $0.1-1$ & 0.4 & 0.5 & 0.5 \\
\hline
\end{tabular}

Table 4 - Summary of NSOs' demographic data

\begin{tabular}{|l|l|l|l|l|l|l|l|}
\hline Characteristics & $\%$ & Number & Range & Mean & Median & Mode \\
\hline PERSONAL DEMOGRAPHICS & \multicolumn{7}{l|l|}{} \\
\hline Sex: & 95 & 18 & & & & \\
\hline Female & 5 & 1 & & & & \\
\hline Male & & & & & & \\
\hline NSO employment in FTE & 58 & 11 & & & & \\
\hline 1.0 FTE & 42 & 8 & & & & \\
\hline 0.5 FTE & & & $1-5$ & 2 & 2 & 2 \\
\hline Number of NUMs supported by each NSO & & & & \\
\hline Service Group - some NSOs worked in multiple wards across different service groups (\# 22 units) & & \\
\hline Medical & 41 & 9 & & & & \\
\hline Surgical & 32 & 7 & & & & \\
\hline Women's \& Families & 13.5 & 3 & & & & \\
\hline Mental Health & 9 & 2 & & & & \\
\hline Clinical Access \& Operations & 4.5 & 1 & & & & \\
\hline
\end{tabular}

This article is protected by copyright. All rights reserved. 
Table 5 - Array of local practices and mechanisms used by NUMs and NSOs

\begin{tabular}{|c|c|}
\hline Practices and mechanisms & Illustrative quotes \\
\hline $\begin{array}{l}\text { Evolving the Role } \\
\text { NUMs and NSOs needed to: } \\
\text { - transition into the roles and their work } \\
\text { practices } \\
\text { - learn how to partner with each other. } \\
\text {-NUMs needed to learn how to let go } \\
\text { and delegate administrative work. }\end{array}$ & $\begin{array}{l}\text {...learning from each other ... because the whole idea of it is to get out there... } \\
\text { and help each other (NSO-18) } \\
\text {...it was a learning curve, it was slow in the start ....until we worked our way along } \\
\text { (NUM-18) } \\
\text {...you have to unlearn a lot of things and re-learn how to be a clinical person } \\
\text { again (NUM-2) } \\
\text {...found it very difficult to delegate some of the things that I had become so used } \\
\text { to doing... (NUM-3) }\end{array}$ \\
\hline $\begin{array}{l}\text { Building Trust } \\
\text {-NUMs and NSOs had to evolve } \\
\text { relationship and build trust. }\end{array}$ & $\begin{array}{l}\text {...developing that trust relationship and knowing how each other works and what } \\
\text { each other does, I think is very, very important, not just having the role, but } \\
\text { getting that relationship happening with that person (NUM-3) } \\
\text {...It's not that they don't trust the NSO, it's that they're so used to doing it } \\
\text { themselves... (NSO-1) } \\
\text { It's building trust. ...it's a building relationship (NSO-5) }\end{array}$ \\
\hline $\begin{array}{l}\text { Setting up Processes } \\
\text { NUMs and NSOs had to find ways to } \\
\text { establish functional relationships, set } \\
\text { up working processes, and } \\
\text { synchronise work }\end{array}$ & $\begin{array}{l}\text { When I was advised that I was getting a NUM Support, the first thing I did put } \\
\text { together my own little package for her... (NUM-1) } \\
\text {...every morning we just have a little chat... roughly plan our day (NSO-6) } \\
\text {... a daily meeting with your NUM to be able to go over what's happening for the } \\
\text { day. Her requirements of your workload and what has to be done (NSO-4) }\end{array}$ \\
\hline $\begin{array}{l}\text { Promoting the role } \\
\text { Both NSOs and NUMs positively } \\
\text { framed the roles in the ward to assist } \\
\text { staff adjustment to the change. }\end{array}$ & $\begin{array}{l}\text {...you say [to staff] "I'm here and I can take that information for you ... I can look it } \\
\text { up... and find out ...instead of waiting to do that with the NUM" (NSO-2) } \\
\text {...Our NSO is part of their team ....she'll attend staff meetings and different things } \\
\text { (NUM-7) }\end{array}$ \\
\hline
\end{tabular}

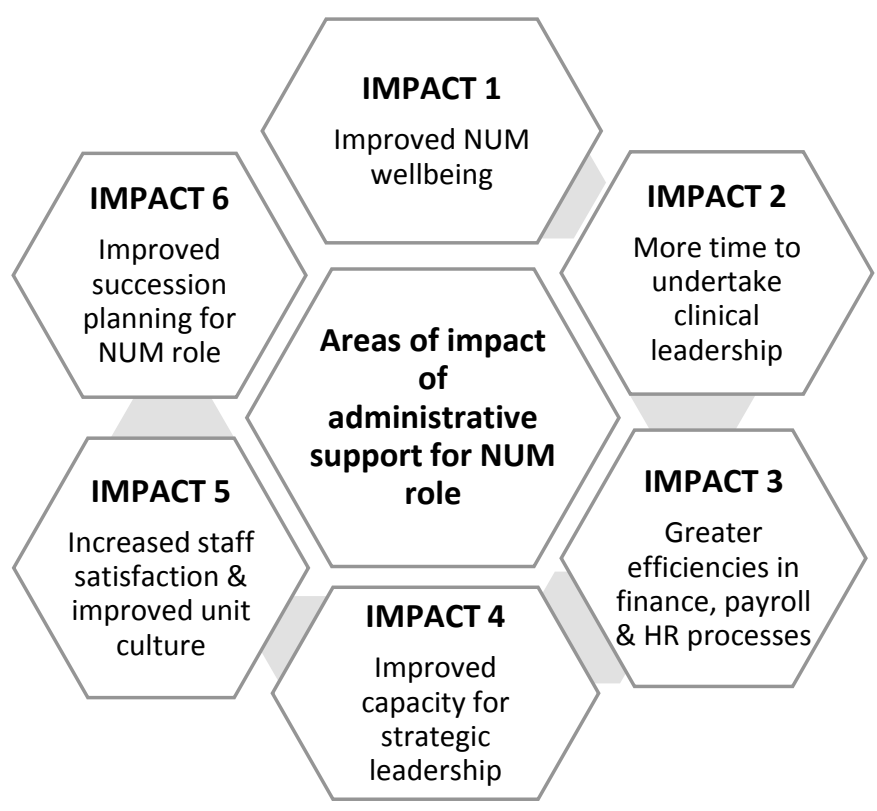

Figure 1: Areas of impact of administrative support for the NUM role

This article is protected by copyright. All rights reserved. 